\title{
Association of epigenetics of the PDK4 gene in skeletal muscle and peripheral blood with exercise therapy following artificial knee arthroplasty
}

Tomohiro Kamo $^{1 *}$, Satoshi Kurose ${ }^{1}$, Hiroshi Ohno ${ }^{2}$, Minoru Murata², Takanori Saito² and Yutaka Kimura ${ }^{1}$

\begin{abstract}
Background: Although exercise is a standard treatment for postoperative osteoarthritis, interindividual differences have been reported. Epigenetic modification (DNA methylation), a factor causing interindividual differences, is altered by the environment and may affect all tissues. Performing a tissue biopsy to investigate methylation of skeletal muscle fat metabolism genes is invasive, and less invasive and convenient alternatives such as blood testing are desired. However, the relationship between tissue and blood is still unclear. Here, we examined the relationship between DNA methylation of the PDK4 gene in skeletal muscle and peripheral blood.
\end{abstract}

Patients and methods: Five patients who underwent artificial knee arthroplasty between April 2017 and June 2018 at Kansai Medical University Hospital were included (2 men and 3 women; average age, 75.2 years; body mass index, $26.1 \mathrm{~kg} / \mathrm{m}^{2}$ ). We measured the body composition of the patients using dual-energy $X$-ray absorptiometry. Peripheral blood was collected at the time of hospitalization and 5 months after surgery; skeletal muscles were collected at the time of surgery and 5 months after surgery. Rehabilitation was performed according to the clinical procedure for 3 months after surgery. Patients performed resistance training and aerobic exercise using an ergometer for 20 min twice a week. Biopsy samples were treated with bisulfite after DNA extraction, and the methylation rate was calculated at different CpG islands downstream from the transcription initiation codon of the PDK4 gene.

Results: No significant change in body composition was observed before and after postoperative exercise therapy, and no significant change was noted in the methylation at each position in the promoter region of PDK4 in the skeletal muscle and peripheral blood. However, changes in the methylation rate at CpG1 in peripheral blood significantly correlated with those in skeletal muscle $(P=0.037)$. Furthermore, the amount of change in the methylation rate of CpG1 in the skeletal muscle was significantly correlated $(P=0.037)$ with the average methylation rate at the promoter region in peripheral blood.

Conclusions: Methylation rates at CpG1 in the skeletal muscle and peripheral blood were significantly correlated, suggesting that skeletal muscle methylation could be analyzed via peripheral blood rather than skeletal muscle biopsy.

Keywords: PDK4 gene, Skeletal muscle, Peripheral blood, Promoter region, Pyrosequencing

\footnotetext{
* Correspondence: kamotom@hirakata.kmu.ac.jp

'Department of Health Science, Kansai Medical University, 2-5-1 Shinmachi, Hirakata, Osaka 573-1010, Japan

Full list of author information is available at the end of the article
}

(c) The Author(s). 2020 Open Access This article is licensed under a Creative Commons Attribution 4.0 International License, which permits use, sharing, adaptation, distribution and reproduction in any medium or format, as long as you give appropriate credit to the original author(s) and the source, provide a link to the Creative Commons licence, and indicate if changes were made. The images or other third party material in this article are included in the article's Creative Commons licence, unless indicated otherwise in a credit line to the material. If material is not included in the article's Creative Commons licence and your intended use is not permitted by statutory regulation or exceeds the permitted use, you will need to obtain permission directly from the copyright holder. To view a copy of this licence, visit http://creativecommons.org/licenses/by/4.0/ The Creative Commons Public Domain Dedication waiver (http://creativecommons.org/publicdomain/zero/1.0/) applies to the data made available in this article, unless otherwise stated in a credit line to the data. 


\section{Background}

Osteoarthritis of the knee (OA knee) is a chronic and degenerative disease of the tissues of the knee joint that negatively affects the quality of daily life of elderly people because of pain during movement and a limited range of motion [1]. Moreover, body weight and fat mass often increase in OA knee patients. To treat and prevent OA knee, weight loss through diet and exercise is important; however, there are interindividual differences in the effectiveness of these measures [2,3]. Genetic and epigenetic factors govern these interindividual differences in training effects. Genetic factors are the direct results of gene expression [4], whereas epigenetic factors regulate gene expression through addition or removal of methyl groups from genes or modification of histones in response to environmental factors $[5,6]$. "Epigenetics" is a concept proposed by Waddington in 1956 [7] that involves DNA modification that controls and maintains gene expression without changes in the DNA sequence itself. Specifically, when a methyl group is added to DNA by the action of DNA methyltransferase, the respective transcription factor cannot bind to the promoter region, and transcription is suppressed. When the methyl group is removed, the transcription factor can bind to the promoter region and promote transcription $[8,9]$. In this system, the type and amount of translated protein are regulated. Even though all cells have the same original base sequence, it is thought that gene expression is highly tissue specific, which enables cells to mature differentially and perform different functions in each organ [10]. Epigenetic modifications depend on the environment and may affect all tissues of the body [11].

The pyruvate dehydrogenase kinase $4(P D K 4)$ gene is associated with lipid metabolism in the skeletal muscle [12]. PDK4 mediates the inactivation of pyruvate dehydrogenase complex (PDC) via phosphorylation. Inactivation of PDC inhibits the conversion from pyruvic acid to acetyl-CoA, thereby shifting the energy substrate utilization from carbohydrate to lipid [13, 14]. DNA methylation in the skeletal muscle plays an important role in gene regulation that depends on CpG methylation in promoter regions [15]. Moreover, hypomethylation of DNA occurs in the CpG island in the promoter region of the PDK4 gene following exercise load in healthy people; this hypomethylation is a short-term effect that improves metabolism [16-19].

We previously investigated the changes in body composition and evaluated the methylation rate of the PDK4 gene using next-generation sequencing (NGS) by performing exercise therapy in human [20]. We found that the exercise-mediated changes in body weight and body fat were associated with changes in the methylation rate of the promoter region and total CpG island [20]. However, NGS is an expensive analysis method and is difficult to perform [21]. Therefore, it is not suitable for clinical application at this point. If the analysis is limited to the promoter region, pyrosequencing would be more cost-effective and clinically feasible than NGS. In addition, it remains unclear whether the observed methylation of the PDK4 gene in skeletal muscle tissue matches that in peripheral blood. If the relationship can be identified, it may not be necessary to invasively collect skeletal muscle tissue; instead, evaluation could be easily performed using peripheral blood. Thus, the current study aimed to calculate the methylation rate using pyrosequencing at each position of the promoter region of the PDK4 gene and to verify the relevance of DNA methylation of the PDK4 gene in skeletal muscle tissue compared with that in peripheral blood.

\section{Methods}

\section{Patients}

The enrolled patients visited the Department of Orthopedics Clinic at Kansai Medical University Hospital and underwent artificial knee arthroplasty between April 2017 and the end of June 2018 for osteoarthritis and osteonecrosis. There were five patients (5 knees), comprising two males and three females with an average age of 75.2 years and an average body mass index of $26.1 \mathrm{~kg} /$ $\mathrm{m}^{2}$ (Table 1). Exclusion criteria were rheumatoid arthritis (RA), mental disorders including dementia, inability to tolerate the exercise regimen, or a history of difficulty performing exercise therapy. This study was performed in accordance with the Declaration of Helsinki, and all procedures were approved by the Ethics Committee of the Kansai Medical University (Approval no. 2016709, date of approval: December 26, 2016). Written informed consent was obtained from all subjects prior to the start of the study.

\section{Body composition}

The body composition of all patients was measured, including total body weight, total body fat mass, and total lean fat mass, using the Lunar Prodigy Advance dualenergy X-ray absorptiometry (DXA) system version 13.6 (GE Healthcare Co., Ltd., Waukesha, WI, USA) at the time of hospitalization and 5 months after surgery.

\section{Peripheral blood collection}

Peripheral blood $(20 \mathrm{cc})$ was collected from the cephalic vein of the elbow before and 5 months after orthopedic surgery at the time of the blood sampling test. Whole blood was stored in a $-80^{\circ} \mathrm{C}$ freezer.

\section{Muscle biopsy}

Muscle biopsy of the affected limb was performed using a midvastus approach during surgery. Approximately 1 $\times 1 \mathrm{~cm}^{2}$ of the vastus medialis muscle was collected, 
Table 1 Patient characteristics and body compositions determined by dual-energy X-ray absorptiometry

\begin{tabular}{llllllllll}
\hline Patient no. & Age (years) & Sex & BMI $\left(\mathrm{kg} / \mathrm{cm}^{2}\right)$ & Pre-TW $(\mathrm{kg})$ & Pre-TFM $(\mathrm{kg})$ & Pre-TLFM $(\mathrm{kg})$ & Post-TW $(\mathrm{kg})$ & Post-TFM $(\mathrm{kg})$ & Post-TLFM $(\mathrm{kg})$ \\
\hline 1 & 74 & F & 29.1 & 69.6 & 31.0 & 36.5 & 67.3 & 28.9 & 36.4 \\
2 & 72 & F & 24.2 & 52 & 18.9 & 31.4 & 51.4 & 18.8 & 30.9 \\
3 & 73 & F & 25.3 & 53.9 & 17.7 & 34.3 & 54.8 & 17.1 & 35.9 \\
4 & 80 & M & 26.3 & 78.2 & 18.8 & 55.9 & 74.7 & 15.3 & 56.2 \\
5 & 77 & M & 25.9 & 70.4 & 19.7 & 48.3 & 67.8 & 20.0 & 45.3 \\
\hline
\end{tabular}

Pre preoperative, Post 5 months postoperative, TW total body weight, BMI body mass index, TFM total body fat mass, TLFM total lean body fat mass

frozen in liquid nitrogen, and stored in a freezer at $-80^{\circ} \mathrm{C}$. At 5 months after surgery, the vastus medialis muscle was visualized under echo guidance at the same site where the biopsy specimen was collected during surgery. After local anesthesia with $1 \%$ Xylocaine ${ }^{\bullet}$ (Astra-Zeneca, Mölndal, Sweden), a needle biopsy was performed on each affected knee with a $14 \mathrm{G}$ biopsy needle (Medicon, Seoul, Korea). The obtained sample was also frozen in liquid nitrogen and stored in a freezer at $-80^{\circ} \mathrm{C}$.

\section{Postoperative exercise therapy}

Postoperative rehabilitative exercise therapy was performed according to the post-TKA/UKA protocol of our institution until 3 months after surgery. After surgery, continuous passive motion was performed until the knee joint movement exceeded $120^{\circ}$. Passive joint movement range exercises, lower limb strength training using $\sim 3$ metabolic equivalents (METs), and walking training for 10 min were carried out in the presence of a physical therapist. From the third month after surgery, patients performed resistance training, mainly involving the quadriceps muscle using $\sim 3$ METs, and an aerobic exercise using a bicycle ergometer at $40-50 \%$ strength according to the Karvonen method calculated from the predicted maximum heart rate. This exercise was performed for 20 min twice a week [22].

\section{Sodium bisulfite modification for DNA methylation analysis}

Skeletal muscle samples were obtained from the affected knees using a QlAamp DNA Mini Kit (Qiagen, Hilden, Germany). Bisulfite-modified gDNA was prepared using the EZ DNA Methylation-Lightning ${ }^{\text {Ts }}$ kit (Zymo Research, Irvine, CA, USA) according to the manufacturer's instructions. The bisulfite reaction was carried out using $200 \mathrm{ng}$ gDNA (adjusted to a volume of $20 \mu \mathrm{l}$ with sterile water) and $130 \mu \mathrm{l}$ of CT Conversion Reagent. The sample tubes were placed in a thermal cycler (Thermo Scientific, Waltham, MA, USA) and subjected to the following conditions: $8 \mathrm{~min}$ at $98^{\circ} \mathrm{C}, 60 \mathrm{~min}$ at $54^{\circ} \mathrm{C}$, and storage at $4{ }^{\circ} \mathrm{C}$ for up to $20 \mathrm{~h}$. The DNA was then purified using reagents contained in the EZ DNA Methylation-Lightning ${ }^{\text {TM }}$ kit (Zymo Research) according to the manufacturer's instructions. The converted gDNA was eluted using $20 \mu \mathrm{l}$ of M-Elution Buffer. DNA samples were finally stored at $-20{ }^{\circ} \mathrm{C}$ until further use.

\section{Pyrosequencing analysis}

We used the bisulfite pyrosequencing method for methylation analyses of the $P D K$ gene. Each primer was designed using Pyrosequencing Assay Design Software v2.0 (Qiagen). PCR amplification was performed on a 76 -base pair region at the -263 position of the PDK4 gene using forward (5'-TTGGGATTAGGGGGGAGAG-3') and reverse (5'-biotin- CAAATTCAAATCTT CCCACCAA-3') primers. Each PCR mix contained 20 ng or more gDNA, PCR premixture (Enzynomics, Daejeon, Korea), $1 \mu \mathrm{l}$ of $10 \mathrm{pmol} / \mu \mathrm{l}$ Primer-S, and $1 \mu \mathrm{l}$ of 10 $\mathrm{pmol} / \mu \mathrm{l}$ biotinylated-Primer-As. The amplification was carried out according to the general guidelines suggested for pyrosequencing: denaturing at $95^{\circ} \mathrm{C}$ for $10 \mathrm{~min}$, followed by 45 cycles at $95^{\circ} \mathrm{C}$ for $30 \mathrm{~s}, 58^{\circ} \mathrm{C}$ for $30 \mathrm{~s}$, and $72{ }^{\circ} \mathrm{C}$ for $30 \mathrm{~s}$, and a final extension at $72{ }^{\circ} \mathrm{C}$ for $5 \mathrm{~min}$. The PCR reaction $(2 \mu \mathrm{l})$ was confirmed by electrophoresis in a $2 \%$ agarose gel and visualized by ethidium bromide staining.

ssDNA templates were obtained with the assistance of the PyroMark ID Vacuum Prep Workstation (Qiagen) according to manufacturer's instructions. Briefly, $16-18 \mu \mathrm{l}$ of the PCR product was immobilized on streptavidin-coated Sepharose ${ }^{\oplus}$ HP beads (Amersham Biosciences, Uppsala, Sweden) and processed to obtain single-stranded DNA. This DNA template was then incubated with $15 \mathrm{pmol}$ of the respective sequencing primer (5'-GATTAGGGGGGAGAGT-3') on the PyroMark ID heat-block at $80^{\circ} \mathrm{C}$ for 2 min. Pyrosequencing was performed on a PyroMark ID system with the Pyro Gold reagents kit (Qiagen) according to the manufacturer's instructions without further optimization.

\section{Statistical analysis}

All data are expressed as mean \pm standard deviation. We compared preoperative and 5-month postoperative measures using the Wilcoxon signed-rank test, including body composition (total weight, total lean mass, and total fat mass) and methylation in the PDK4 gene in the skeletal muscle and peripheral blood; each position was expressed as 56 bp (CpG1), 76 bp (CpG2), 80 bp (CpG3), 
83 bp (CpG4), and 86 bp (CpG5) downstream from the transcription initiation codon of the $\mathrm{CpG}$ island in the promoter region. Then, the methylation rate of each position was calculated and compared using the Wilcoxon signed-rank test. In addition, the relationship between age, the change in body composition, and the change in the PDK4 methylation rate on the $\mathrm{CpG}$ island in peripheral blood and the skeletal muscle before and after surgery was evaluated using Spearman's rank correlation coefficient. All statistical analyses were performed using SPSS software version 25.0 for Mac OS (IBM Corp., Armonk, NY, USA). $P<0.05$ was considered statistically significant in all analyses.

\section{Results}

\section{Changes in body composition}

Analysis after surgery indicated that the total body weight had changed from $64.8 \pm 11.4 \mathrm{~kg}$ to $63.2 \pm 9.7 \mathrm{~kg}$ $(P=0.14)$, total body fat mass changed from $21.2 \pm 5.5$ $\mathrm{kg}$ to $20.0 \pm 5.3 \mathrm{~kg}(P=0.14)$, and total lean body fat mass changed from $41.3 \pm 10.4 \mathrm{~kg}$ to $41.0 \pm 10.0 \mathrm{~kg}(P=$ 0.69 ), as measured by DXA. These three parameters were not significantly different between before and 5 months after surgery.

\section{PDK4 methylation results}

The CpG island region of PDK4 is shown in Fig. 1. A total of $77 \mathrm{CpG}$ sites were sequenced. The promoter region of the PDK4 gene from the Swiss Institute of Bioinformatics (Lausanne, Switzerland) comprises $60 \mathrm{bp}$ (5'-GAGAGTGCGGGGAGACAAAACCTCGGGCGGC GGCGGCTGGGAAGACTTGAACT-3') from $49 \mathrm{bp}$ to 108 bp downstream of the transcription initiation codon (Fig. 1). Analysis of the PDK4 gene in the promoter region using peripheral blood indicated changes in the methylation rates as follows: CpG1 $(8.2 \pm 5.45 \%$ to $9.4 \pm$ $1.65 \%, P=0.50)$, CpG2 (7.1 $\pm 2.96 \%$ to $6.3 \pm 2.53 \%, P=$ $0.89), \mathrm{CpG} 3(6.6 \pm 5.01 \%$ to $7.7 \pm 1.96 \%, P=0.50)$, CpG4 (7.6 $\pm 3.48 \%$ to $8.3 \pm 1.52 \%, P=0.50)$, CpG5 (6.2 $\pm 4.93 \%$ to $7.4 \pm 1.55 \%, P=0.50)$, and the average of the promoter region (CpG1-5 average) $(7.2 \pm 4.06 \%$ to $7.8 \pm$ $1.48 \%, P=0.50)$; these changes were not significantly different from preoperation to 5 months postoperation. Analysis of the PDK4 gene in the promoter region in the skeletal muscle indicated the following changes: $\mathrm{CpG1}$ $(1.1 \pm 1.06 \%$ to $2.2 \pm 0.48 \%, P=0.08), \mathrm{CpG} 2(3.7 \pm$ $1.26 \%$ to $3.3 \pm 0.88 \%, P=0.23), \mathrm{CpG} 3(0.5 \pm 1.10 \%$ to $0.3 \pm 0.74 \%, P=0.66)$, CpG4 $(1.3 \pm 2.24 \%$ to $1.7 \pm$ $0.47 \%, P=0.50)$, CpG5 $(0.9 \pm 2.05 \%$ to $1.3 \pm 1.18 \%, P=$ $1.00)$, and the average of the promoter region (CpG1-5 average) $(1.5 \pm 1.44 \%$ to $1.8 \pm 0.34 \%, P=0.50)$; these changes were also not significant between preoperation to 5 months postoperation.

However, as shown in Fig. 2, there was a significant positive correlation $(r=0.90, P=0.04)$ between the change in methylation rate in $\delta \mathrm{CpG1}$ in peripheral blood and that in the skeletal muscle. Furthermore, there was a significant positive correlation $(r=0.90, P=0.04)$ between the change in the $\delta$ CpG1 skeletal muscle methylation rate and the change in the methylation rate of the Spromoter region (CpG1-5 Average) in peripheral blood (Fig. 3). The difference in the amount of change between the skeletal muscle and peripheral blood was as follows: ¿CpG1 (skeletal muscle vs. peripheral blood) (1.2 \pm $4.80 \%$ vs. $1.1 \pm 1.15 \%, P=0.89), \delta \mathrm{CpG} 2(-0.9 \pm 4.5 \%$ vs. $-0.4 \pm 0.58 \%, P=0.89), \delta$ CpG3 $(1.1 \pm 4.7 \%$ vs. $-0.16 \pm$ $1.47 \%, P=0.50)$, $\delta$ CpG4 $(0.72 \pm 3.0 \%$ vs. $0.4 \pm 2.26 \%, P$ $=0.89), \delta$ CpG5 $(1.2 \pm 4.4 \%$ vs. $0.4 \pm 1.9 \%, P=0.50)$, and average of $\delta$ promoter region (CpG1-5 Average) (0.7 \pm $3.8 \%$ vs. $0.3 \pm 1.19 \%, P=0.69$ ); these differences were not significantly different. In addition, there was no significant correlation between age and each position of

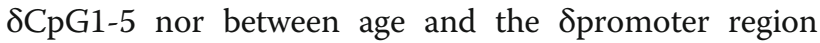
(CpG1-5 Average) in peripheral blood and muscle.

\section{Discussion}

Although we investigated epigenetic modifications related to postoperative exercise therapy using the skeletal

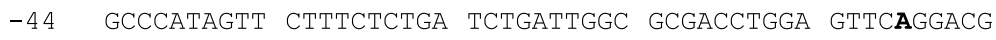

$$
\begin{aligned}
& \text { +6 CGTtTCCAAG TTCCAGTGAC TCCTCCTGTT TGGGACTCGg GGGGAGAGTG } \\
& \text { +56 CGGGGAGACA AATAAAACCT CGGGCGGCGG CGGCTGGTGG GAAGACTTGA } \\
& \text { +106 ACTTGAATCT CGAACCACTG CATCTCCGAC TCTGCCCAGA CTCTTCACTC } \\
& \text { +156 CGCGGCACCC TCAAACCCCA GCCCAGGCCG GGGCGCACAA GCCAGCCAGC } \\
& \text { +206 GCACCTGCAg TCCTCGCCCG GACGCGCCGC GCCCCCTCGg AACCAGGCTC } \\
& \text { +256 TGCTCCGAGC AGCCTTCGCC CCTCAAGCCA GCCACAGTCC CCGCCAGGCC } \\
& \text { +306 GGgtgGgCGT CAAGATgAag GCGGCCCGCT tCGTGCTGCG CAGCGCTGGC }
\end{aligned}
$$

Fig. 1 The CpG island region of the PDK4 gene. The circled C represents cytosine reacted with bisulfite. The circled C is defined as CpG1, CpG2, $\mathrm{CpG}$, and $\mathrm{CpG} 4$, in that order. $\mathbf{A}$ is the transcription initiation codon. ATG is the translation initiation codon. The underlined portion is the promoter region of the PDK4 gene 


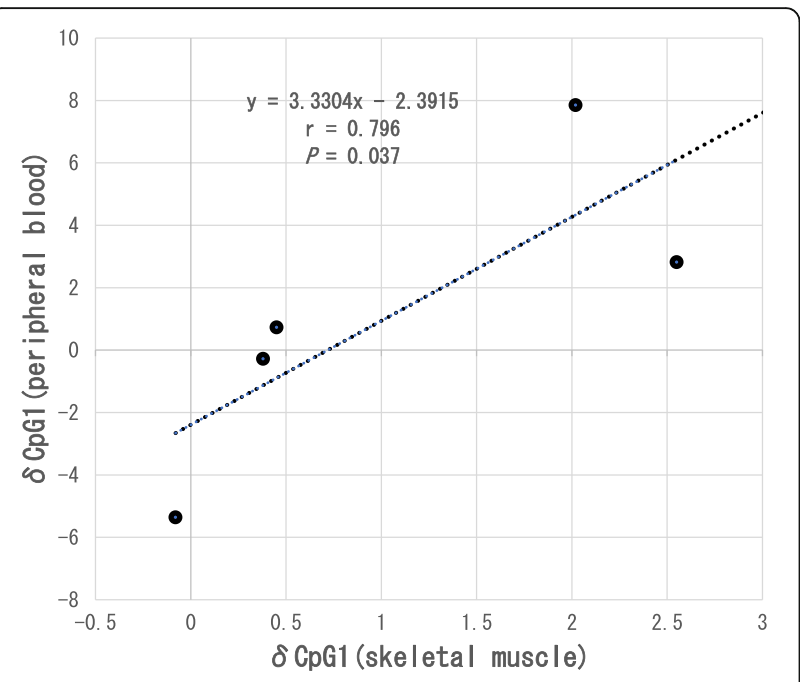

Fig. 2 Correlation between the change in $\delta C p G 1$ in the skeletal muscle and that in peripheral blood. Statistical analysis was performed using Spearman's rank correlation coefficient

muscle, such biopsies are painful and cause bleeding. If epigenetic modifications can be investigated via a blood test, the evaluation can be performed very easily and in a less invasive manner. However, the relationship between the skeletal muscle and blood is unclear. In CpG1, there was a significant positive correlation between the change in skeletal muscle methylation rate and the change in peripheral blood methylation rate. Furthermore, the change in the CpG1 skeletal muscle methylation rate was significantly positively correlated with the change in the average methylation rate of the promoter region in

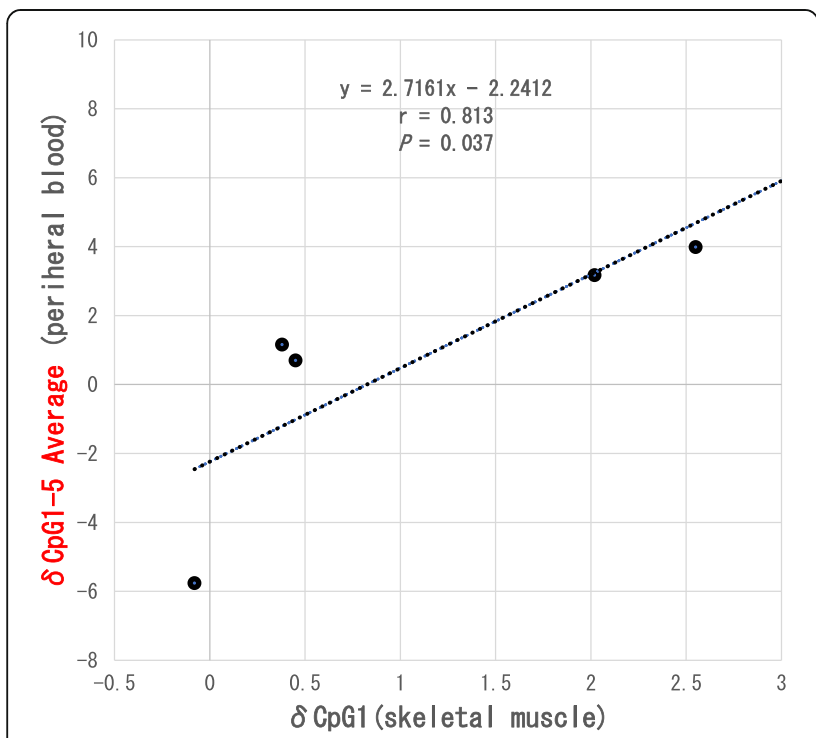

Fig. 3 Correlation between changes in $\delta C p G 1$ in the skeletal muscle and the Spromoter region in the peripheral blood. Statistical analysis was performed using Spearman's rank correlation coefficient peripheral blood. Moreover, there was no significant difference in the amount of change between the skeletal muscle and peripheral blood. Based on the above, we speculated that CpG1 may be involved in methylation of the promoter region in the two tissues. Since PDK4 is mainly present in the skeletal muscle and DNA methylation is highly tissue specific, it is common to collect and analyze the skeletal muscle [23]. However, Dayeh et al. reported that these epigenetic modifications altered by the physical and biological environment may affect all tissues of the body, and further, DNA methylation biomarkers in the blood may be used as surrogate markers for DNA methylation in inaccessible target tissues [24]. We also considered that lipid metabolism may affect the total fat mass via methylation of the PDK4 gene and that evaluation with peripheral blood is possible. Therefore, it was considered clinically important to verify the methylation rate in both the skeletal muscle and peripheral blood tissues.

Our analysis revealed that methylation of CpG1 in the PDK4 gene in the skeletal muscle might be associated with the average methylation rate of the total promoter region in the peripheral blood. However, its mechanism remains unclear because there are no studies that investigated the association between methylation differences in elderly skeletal muscle and peripheral blood samples. Pyrosequencing can be used to evaluate the methylation rate at each position in the same way as NGS [25], unlike conventional Sanger capillary sequencing [26, 27]. Pyrosequencing is different from NGS in that it can process a huge amount of data at high speed. The method is suitable for investigating $\mathrm{CpG}$ sites in a small region of DNA in a limited number of samples and genomic target regions and is considered to be costeffective. As we investigated only the promoter region, we used pyrosequencing and revealed that CpG1 in the skeletal muscle PDK4 gene might be associated with PDK4 methylation in the peripheral blood.

We have previously reported the relationship between postoperative exercise therapy and body composition in elderly patients with OA knee by calculating the methylation rate of the PDK4 gene, which controls the skeletal muscle and fat metabolism. We considered the possibility that the derived methylation rate could be one of the indicators of exercise therapy [21]. In postoperative exercise therapy, body composition did not change significantly based on DXA, and the promoter region of the PDK4 gene in the skeletal muscle and peripheral blood did not change significantly. Barres et al. reported that exercise results in hypomethylation in the promoter region of the PDK4 gene [16]. In this study, postoperative exercise therapy did not change the body composition of the patients. The reason may be that the exercise intensity could not be increased for these elderly patients, and 
the amount of exercise performed by each individual was small. Therefore, the exercise regimen may not have been sufficient to cause hypomethylation in the promoter region of the PDK4 gene. In fact, body fat mass did not change significantly, and its influence is considered to be sufficient. Constantin et al. stated that the transcription of the PDK4 gene inhibits PDC and suppresses the metabolism of pyruvate to acetyl-CoA [28]. It is possible that this process contributed to the reduction of body fat mass and weight loss through the activation of fatty acid oxidation by $\beta$-oxidation. If the body fat content decreased with body composition, it is possible that hypomethylation occurred in the promoter region.

There are several limitations to this study. First, the number of samples was small, and we did not include a control group. In this study, postoperative rehabilitation and exercise therapy were absolutely necessary treatments for all patients. Furthermore, it was extremely invasive and ethically impossible to perform similar tests, including muscle biopsy, on healthy individuals. In other words, it is possible that the change was only related to time or due to the dispersion of the measured value, and it cannot be denied that the result may change upon increasing the number of samples. Nonetheless, this is the first pilot study to investigate the methylation rate of each position of the $\mathrm{CpG}$ island in the promoter region of the PDK4 gene as well as the correlation of the methylation rates between tissues. Therefore, we believe that these results are highly important, but large-scale research is needed to validate our findings. Second, we could perform exercise therapy for only 5 months due to the Japanese insurance system; in this period, we were unable to observe any changes in body composition during postoperative exercise therapy. Another limitation is that the subjects were elderly OA knee patients, and it is unclear whether similar outcomes would be obtained in young people. However, previous studies have reported that various genes are affected by methylation due to exercise in sedentary young people [16, 29, 30]. Fourth, methylation at positions other than the promoter region, i.e., in the non-promoter region, may be involved in PDK4 gene transcription. Our previous study in patients who underwent exercise therapy after artificial knee arthroplasty also caused hypomethylation in the nonpromoter region by exercising [20].. Pheiffer et al. reported that the non-promoter region has various transcriptional regulators [31]. However, the promoter region is most involved in transcription, and many previous studies used hypomethylation at the promoter region as a criterion; thus, it is appropriate for use in methylation analysis $[16,20,29,30]$. Unlike NGS, pyrosequencing could not be used to comprehensively verify $\mathrm{CpG}$ islands, and therefore it was unclear whether the non-promoter region was involved. In addition, we could not evaluate mRNA, miRNA, or the protein involved in the expression of the PDK4 gene. In the future, we plan to evaluate not only methylation but also histone modifications. Furthermore, by clarifying the mechanism behind protein expression of PDK4, it may be possible to understand fat metabolism mediated by the PDK4 gene in more depth. Finally, methylation may also be affected by factors other than exercise. In this study, all patients received similar surgical procedures and rehabilitation, and pain relief was achieved; however, it was difficult to standardize dietary intake, and the only lifestyle intervention included exercise therapy. Nonetheless, the results of this study were likely attributable to the exercise therapy.

In this study, we utilized pyrosequencing as a costeffective alternative to NGS; however, this method is still expensive and involves complicated procedures [32, 33]. Therefore, it is necessary to reduce costs and simplify procedures for widespread clinical application.

\section{Conclusion}

The change in CpG1 methylation rate in the promoter region of PDK4 in the skeletal muscle and in the peripheral blood following exercise therapy for 5 months postsurgery showed a significant positive correlation. Furthermore, the change in the methylation rate of the CpG1 region in the skeletal muscle showed a significant positive correlation with that of the average of the promoter region in the peripheral blood. These results suggested that the determination of the methylation rate of the PDK4 gene by skeletal muscle analysis could be substituted by less invasive examination of the peripheral blood.

\section{Abbreviations}

DXA: Dual-energy X-ray absorptiometryMETsMetabolic equivalentsNGSNextgeneration sequencingOA kneeOsteoarthritis of the kneePDCPyruvate dehydrogenase complexRARheumatoid arthritis

\section{Acknowledgements \\ We would like to thank the patients who participated in the present study. We express our gratitude for the assistance of staff members of the Health Science Center, Orthopedic and Rehabilitation of Kansai Medical University Hospital.}

\section{Authors' contributions}

TK wrote the manuscript. TK, HO, and MM performed biopsies. YK contributed to the study design. SK helped to carry out the experiments and analyze the data. SK, TS, and YK participated in designing and coordinating the experiments and helped to draft the manuscript. TK, SK, HO, MM, TS, and YK conceived the study, participated in its design and coordination, and helped draft the manuscript. All authors have read and approved the final manuscript. This study was approved by the Ethics Committee of Kansai Medical University (approval number: 2016709). 


\section{Availability of data and materials}

The datasets used and analyzed during the current study are available from the corresponding author on reasonable request.

\section{Ethics approval and consent to participate}

All procedures performed involving human participants were in accordance with the ethical standards of the institutional research committee and the 1964 Helsinki Declaration and its later amendments or comparable ethical standards. Informed consent was obtained from all individual participants included in the study.

\section{Consent for publication}

Not applicable.

\section{Competing interests}

The authors declare that they have no competing interests.

\section{Author details}

'Department of Health Science, Kansai Medical University, 2-5-1 Shinmachi, Hirakata, Osaka 573-1010, Japan. ${ }^{2}$ Department of Orthopaedic Surgery, Kansai Medical University Hospital, 2-5-1 Shinmachi, Hirakata, Osaka 573-1010, Japan.

Received: 31 December 2019 Accepted: 10 March 2020

Published online: 26 March 2020

\section{References}

1. Felson DT, Zhang Y, Hannan MT, Naimark A, Weissman BN, Aliabadi P, et al. The incidence and natural history of knee osteoarthritis in the elderly. The Framingham Osteoarthritis Study. Arthritis Rheum. 1995;38:1500-5.

2. Bouchard C, Rankinen T. Individual differences in response to regular physical activity. Med Sci Sports Exerc. 2001;33:446-51.

3. American College of Sports Medicine, Chodzko-Zajko WJ, Proctor DN, Fiatarone Singh MA, Minson CT, Nigg CR, et al. American College of Sports Medicine position stand. Exercise and physical activity for older adults. Med Sci Sports Exerc. 2009;41:1510-30.

4. Rankinen T, Pérusse L, Rauramaa R, Rivera MA, Wolfarth B, Bouchard C. The human gene map for performance and health-related fitness phenotypes. Med Sci Sports Exerc. 2001;33:855-67.

5. Goldberg AD, Allis CD, Bernstein E. Epigenetics: a landscape takes shape. Cell. 2007:128:635-8.

6. Lawrence RJ, Earley K, Pontes O, Silva M, Chen ZJ, Neves N, et al. A concerted DNA methylation/histone methylation switch regulates rRNA gene dosage control and nucleolar dominance. Mol Cell. 2004;13:599-609.

7. Waddington $\mathrm{CH}$. Genetic assimilation of the bithorax phenotype. Evolution. 1956;10:1-13.

8. Reik W. Stability and flexibility of epigenetic gene regulation in mammalian development. Nature. 2007:447:425-32.

9. Bird A. Perceptions of epigenetics. Nature. 2007:447:396-8.

10. Shiota K. DNA methylation profiles of CpG islands for cellular differentiation and development in mammals. Cytogenet Genome Res. 2004;105:325-34.

11. Seaborne RA, Strauss J, Cocks M, Shepherd S, O'Brien TD, van Someren KA, et al. Human skeletal muscle possesses an epigenetic memory of hypertrophy. Sci Rep. 2018;8:1898.

12. Pilegaard H, Keller C, Steensberg A, Helge JW, Pedersen BK, Saltin B, et al. Influence of pre-exercise muscle glycogen content on exercise-induced transcriptional regulation of metabolic genes. J Physiol. 2002;541:261-71.

13. Bowker-Kinley MM, Davis WI, Wu P, Harris RA, Popov KM. Evidence for existence of tissue-specific regulation of the mammalian pyruvate dehydrogenase complex. Biochem J. 1998;329:191-6.

14. Sugden MC, Holness MJ. Recent advances in mechanisms regulating glucose oxidation at the level of the pyruvate dehydrogenase complex by PDKs. Am J Physiol Endocrinol Metab. 2003;284:855-62.

15. Carrió E, Suelves M. DNA methylation dynamics in muscle development and disease. Front Aging Neurosci. 2015;7:19.

16. Barrès R, Yan J, Egan B, Treebak JT, Rasmussen M, Fritz T, Caidahl K, et al. Acute exercise remodels promoter methylation in human skeletal muscle. Cell Metab. 2012:15:405-11.

17. Nitert MD, Dayeh T, Volkov P, Elgzyri T, Hall E, Nilsson E, et al. Impact of an exercise intervention on DNA methylation in skeletal muscle from firstdegree relatives of patients with type 2 diabetes. Diabetes. 2012;61:3322-32
18. Turner DC, Seaborne RA, Sharples AP. Comparative transcriptome and methylome analysis in human skeletal muscle anabolism, hypertrophy and epigenetic memory. Sci Rep. 2019;9:4251.

19. Rowlands DS, Page RA, Sukala WR, Giri M, Ghimbovschi SD, Hayat I, et al. Multi-omic integrated networks connect DNA methylation and miRNA with skeletal muscle plasticity to chronic exercise in Type 2 diabetic obesity. Physiol Genomics. 2014;46:747-65.

20. Kamo T, Kurose S, Ohno H, Murata M, Hashiyada M, Saito T, et al. Epigenetic mechanism controls PDK4 gene activation before and after exercise therapy following artificial knee arthroplasty. Clin Interv Aging. 2019;14:1433-43.

21. Reiman A, Kikuchi H, Scocchia D, Smith P, Tsang YW, Snead D, et al. Validation of an NGS mutation detection panel for melanoma. BMC Cancer. 2017;17:150

22. Karvonen MJ, Kentala $\mathrm{E}$, Mustala $\mathrm{O}$. The effects of training on heart rate; a longitudinal study. Ann Med Exp Biol Fenn. 1957:35:307-15.

23. Pilegaard H, Osada T, Andersen LT, Helge JW, Saltin B, Neufer PD. Substrate availability and transcriptional regulation of metabolic genes in human skeletal muscle during recovery from exercise. Metabolism. 2005;54:1048-55.

24. Dayeh T, Tumi T, Almgren P, Perfilyev A, Jansson PA, de Mello VD, et al. DNA methylation of loci within ABCG1 and PHOSPHO1 in blood DNA is associated with future type 2 diabetes risk. Epigenetics. 2016;11:482-8.

25. Ronaghi M, Nygren M, Lundeberg J, Nyrén P. Analyses of secondary structures in DNA by pyrosequencing. Anal Biochem. 1999;267:65-71.

26. Sanger $F$, Nicklen $S$, Coulson AR. DNA sequencing with chain-terminating inhibitors. Proc Natl Acad Sci U S A. 1977;74:5463-7.

27. Shendure J, Ji H. Next-generation DNA sequencing. Nat Biotechnol. 2008;26: $1135-45$.

28. Constantin-Teodosiu D, Constantin D, Stephens F, Laithwaite D, Greenhaff PL. The role of FOXO and PPAR transcription factors in diet-mediated inhibition of PDC activation and carbohydrate oxidation during exercise in humans and the role of pharmacological activation of PDC in overriding these changes. Diabetes. 2012;61:1017-24.

29. Rönn T, Volkov P, Davegårdh C, Dayeh T, Hall E, Olsson AH, et al. A six months exercise intervention influences the genome-wide DNA methylation pattern in human adipose tissue. PLoS Genet. 2013;9:e1003572.

30. Lindholm ME, Marabita F, Goez-Cabrero D, Rundqvist H, Ekström TJ, Tegnér J, et al. An integrative analysis reveals coordinated reprogramming of the epigenome and the transcriptome in human skeletal muscle after training. Epigenetics. 2014;9:1557-69.

31. Pheiffer C, Erasmus RT, Kengne AP, Matsha TE. Differential DNA methylation of microRNAs within promoters, intergenic and intragenic regions of type 2 diabetic, pre-diabetic and non-diabetic individuals. Clin Biochem. 2016;49: 433-8.

32. Grada A, Weinbrecht K. Next-generation sequencing: methodology and application. J Invest Dermatol. 2013;133:e11.

33. Groth M, Huse K, Reichwald K, Taudien S, Hampe J, Rosenstiel P, et al. Method for preparing single-stranded DNA templates for Pyrosequencing using vector ligation and universal biotinylated primers. Anal Biochem. 2006;356:194-201

\section{Publisher's Note}

Springer Nature remains neutral with regard to jurisdictional claims in published maps and institutional affiliations.

Ready to submit your research? Choose BMC and benefit from:

- fast, convenient online submission

- thorough peer review by experienced researchers in your field

- rapid publication on acceptance

- support for research data, including large and complex data types

- gold Open Access which fosters wider collaboration and increased citations

- maximum visibility for your research: over $100 \mathrm{M}$ website views per year

At $\mathrm{BMC}$, research is always in progress.

Learn more biomedcentral.com/submissions 